\title{
Adherence to recommended clinical guidelines in extensive disease small-cell lung cancer across the US, Europe, and Japan
}

This article was published in the following Dove Medical Press journal: Therapeutics and Clinical Risk Management

\author{
Marco D DiBonaventura' \\ Bijal Shah-Manek ${ }^{2}$ \\ Karen Higginbottom' \\ John R Penrod ${ }^{3}$ \\ Yong Yuan ${ }^{3}$ \\ 'Global Evidence Value and Access \\ (GEVA), Ipsos Healthcare, Mahwah, \\ NJ, USA; ${ }^{2}$ Global Evidence Value and \\ Access (GEVA), Ipsos Healthcare, \\ San Francisco, CA, USA; ${ }^{3}$ Worldwide \\ Health Economics and Outcomes \\ Research, Bristol-Myers Squibb, \\ Princeton, NJ, USA
}

Purpose: This study compared real-world treatment patterns of patients with extensive disease small-cell lung cancer (ED-SCLC) across regions and by platinum resistance/platinum sensitivity (PR/PS) and established if these patterns were in line with published guidelines.

Patients and methods: The data source was the Oncology Monitor, a global database using retrospective medical chart reviews of oncology patients treated with anticancer drugs. All patients diagnosed with ED-SCLC from January 2014 through December 2016 in the US, and in France, Germany, Italy, Spain, and the UK (European Union; EU5), and Japan were included. Results: Of 5,849 treated patients, $73.4 \%, 19.8 \%$ and $6.8 \%$ received first, second, or third/later lines (1L, 2L, 3L) of therapy, respectively. The most frequent $1 \mathrm{~L}$ treatment, platinum + etoposide, was significantly more common in the US $(87.0 \%)$ than in the EU5 $(82.1 \%)$ or Japan $(73.3 \%)$ $(P<0.05)$. Platinum + irinotecan was a common $1 \mathrm{~L}$ treatment in Japan $(22.7 \%)$ but not in the US $(2.0 \%)$ or EU5 $(0.5 \%, P<0.0001)$. Topotecan was the most common $2 \mathrm{~L}$ treatment in the US and EU5, but amrubicin was the most common in Japan. Among PR patients, 27.3\%, 10.8\%, and 36.4\% received a platinum-based 2L therapy in the US, EU5, and Japan, respectively. Among PS patients, approximately half were not re-challenged with a $2 \mathrm{~L}$ platinum-based therapy across all regions.

Conclusion: In contrast to treatment guidelines, a significant proportion of real-world PR patients were re-challenged with a $2 \mathrm{~L}$ platinum-based therapy, while conversely, many PS patients did not receive platinum-based therapies in $2 \mathrm{~L}$. This study highlights a lack of a consistent paradigm for 2L ED-SCLC treatment, limited therapeutic options, and an unmet need among SCLC patients. Keywords: small-cell lung cancer, real-world treatment patterns, clinical guidelines

\section{Introduction}

In the US, small cell lung cancer (SCLC) comprises approximately $13 \%$ of all lung cancer cases, with nearly 30,000 patients diagnosed annually. ${ }^{1,2}$ Similar, although slightly lower, rates have been reported outside the US, with small-cell lung cancer (SCLC) cases in England accounting for $10 \%$ and $11 \%$ of all lung cancer in males and females in 2007 , respectively. ${ }^{3}$ In Japan, a recent study reported incidence rates of SCLC to be trending downward, with age-standardized rates per 100,000/year of approximately 70 for males and 30 for females. ${ }^{4}$ Tobacco use has been consistently associated with SCLC and, when accompanied by mutant tumor suppressor p53 (TP53), can represent particularly aggressive disease. . $^{5}$

Patients with SCLC often (up to $70 \%$ of the time) present with extensive disease at diagnosis, which is defined as any patient with distant metastasis as per International Association for the Study of Lung Cancer (IASLC) staging guidelines. ${ }^{7}$ Less than $7 \%$ of all SCLC patients survive 5 years, and less than $5 \%$ of patients with extensive disease survive 2 years. ${ }^{8}$ Many patients become resistant to chemotherapy
Correspondence: Bijal Shah-Manek Noesis Healthcare Technologies, 49 Stevenson Street, 15th Floor, San Francisco, CA 94105, USA

Tel + I 7073 I5 1870

Email bijal@noesis.care 
regimens, likely due to the high genomic instability of this type of tumor, and thus are left with few treatment options. ${ }^{9}$ Given the aggressive nature of SCLC, patients often experience high levels of multi-symptom burden, including shortness of breath, fatigue and pain. ${ }^{10}$ Comorbid disease is also common, including hypertension, cardiac disease, COPD, and diabetes, and has been shown to be an independent prognostic marker in certain disease subtypes. ${ }^{11}$

Unfortunately, there are few treatment options for patients with SCLC. In contrast to non-small-cell lung cancer (NSCLC), in which there have been an increasing number of treatment advances, very few have been made in SCLC. ${ }^{6}$ This lack of advancement is evidenced by over 40 Phase III clinical trial failures in the past several decades. ${ }^{6}$

Guidelines for treatment in SCLC have been published by the National Comprehensive Cancer Network (NCCN) and European Society for Medical Oncology (ESMO), and endorsed by the Japanese Society for Medical Oncology. ${ }^{12,13}$ For patients with extensive disease, platinum-based chemotherapy remains the preferred first-line (1L) option. Most patients in the US, France, Germany, Italy, Canada, UK, and Japan receive platinum + etoposide (EP) chemotherapy. In some countries, guidelines dictate that patients may receive platinum + irinotecan or platinum in combination with a taxane. ${ }^{12}$

Treatment decision-making among this patient population remains challenging. Second-line (2L) therapies often consist of topotecan monotherapy or platinum + taxane, or anthracycline-based therapies; however, clinical investigations are ongoing, and controversy exists regarding the benefit associated with platinum vs non-platinum based therapies and the most appropriate $2 \mathrm{~L}$ treatment for patients with refractory disease. ${ }^{14,15}$ Patients who relapse more than 6 months after $1 \mathrm{~L}$ treatment are considered platinum-sensitive (PS) and are recommended to be re-challenged with their initial therapy. In contrast, patients who relapse within 3 months are considered platinum-refractory or resistant (PR), and guidelines recommend that such patients be treated with a non-platinum based therapy. Less evidence and consequent guidance exists for patients who relapse between 3 and 6 months post-1L treatment.

Few real-world studies have evaluated treatment patterns based on PS and PR, and the majority of existing published evidence comes from studies with small sample sizes or a nonrandomized study design. ${ }^{14-16,18}$ A recently published real-world study in the US suggested nearly $90 \%$ of elderly patients (ie, those $\geq 65$ years) were receiving EP in $1 \mathrm{~L}$ with topotecan monotherapy (nearly 40\%) and EP (nearly 20\%), the most common $2 \mathrm{~L}$ treatments. ${ }^{17}$ Rates of response were low among patients receiving 3L treatment (18\%), as well as for the approximately $5 \%$ of patients who progress within 3 months of completing EP in 1L. ${ }^{18}$

Despite the poor prognosis, limited treatment advances, and challenges in $2 \mathrm{~L}$ treatment among those diagnosed with SCLC, there is a paucity of research comparing treatment patterns across regions, or examining the possible influence of platinum sensitivity on prescribed therapy.

The objective of the current study was to extend understanding of real-world treatment patterns of patients with SCLC in the US, EU5 and Japan, and examine how these patterns might vary as a function of line of therapy and PS, and the degree to which they align with published treatment guidelines.

\section{Material and methods Data source}

Data from the Oncology Monitor(OM; Ipsos Healthcare) were used for this study. The OM is a clinical database of oncology patients collected through retrospective medical chart review abstraction. The OM data is owned and maintained by Ipsos. Since the OM data is a secondary, deidentified data source, it is exempt from approval by the IRB/ethics committee. Physicians were recruited from Ipsos Healthcare panels (US: N=468; EU5 (France, Germany, Italy, Spain, and UK): $\mathrm{N}=472$; Japan: $\mathrm{N}=447$ as of 2016) based on their demographic and practice characteristic mix generalizing to the oncologytreating population. For example, in the US the distribution of setting is $60 \%$ office, $20 \%$ university hospital, $10 \%$ comprehensive cancer center, $10 \%$ community hospital, and $1 \%$ veteran's affairs hospital. In the EU5, targets for recruitment are set by region, office or hospital location, or public vs private practice where applicable. In Japan, the regional focus is on Kanto, Kansai-Chubu, Northern, and Southern regions where physicians are recruited from $200+$ bed institutions. These physicians treat $80 \%$ of cancer cases in Japan.

Physicians who participate in the OM study are asked to select charts of patients most recently seen who were receiving an anticancer regimen. They select between 7 and 40 charts per month of participation (but are not required to participate every month). Limits are imposed to the number of physicians per site to ensure representativeness within each country. Specifically, no more than 4 physicians from large cancer centers and no more than 2 physicians from all other practices can participate from the same site.

Study physicians are asked to select charts of patients recently seen who were receiving an anticancer regimen (7-40 charts per month). For each patient selected, the physician abstracts the clinical information from the patient chart into an online data collection form (in Japan, however, a paper-based data collection form is used). Approximately, 
$\mathrm{N}=4,500$ and $\mathrm{N}=3,500$ patient charts are entered each month in the US and EU5, respectively. Physicians in Japan complete approximately 5,900 patient forms each quarter. OM data have been used in several prior publications exploring epidemiological trends, treatment patterns, and clinical outcomes. ${ }^{19-21}$ The data have been included in regulatory and reimbursement submissions, eg, with the Ministry of Health, Labor, and Welfare (Japan) and Pharmaceuticals and Medical Devices Agency (Japan).

\section{Ethical approval}

All procedures performed in studies involving human participants were in accordance with the ethical standards of the institutional and/or national research committee and with the 1964 Helsinki Declaration and its later amendments or comparable ethical standards.

\section{Informed consent}

Data used in this study were from the Ipsos Oncology Monitor, an ongoing retrospective chart review study. As such, no informed consent was obtained from individual participants, as no personally identifiable health information was collected.

\section{Sample}

The present study only included patient charts with SCLC which were collected from January 2014 through to December $2016(\mathrm{~N}=6,936)$. All patients in the OM database are diagnosed with a form of cancer and are actively receiving an anticancer regimen. This study only included patients diagnosed with SCLC and those whose most recent visit to their oncologist occurred between January 2014 and December 2016. While the sample of SCLC patients used for this study is not a randomized or population-based sample, it is a sample from a large dataset that reflects the specialty, practice, and types of cancer populations in the US, EU5, and Japan.

\section{Measures}

\section{Demographics and general health history}

The following information was collected: country, age, sex, race/ethnicity, height and weight to calculate body mass index, body surface area, smoking history, and the presence of the following comorbidities: renal disease, hepatic disease, pulmonary disease, diabetes, hypertension, cardiovascular disease, thyroid disease, obesity, depression, and dementia/ Alzheimer's disease.

\section{Disease history}

Date of diagnosis, stage at diagnosis, current stage, current Eastern Cooperative Oncology Group (ECOG) performance status, and location of metastases (distant lymph nodes, liver, bone, brain, lung, or other).

\section{Treatment history}

Prior history of surgery and radiation therapy was recorded for each patient. Specific anticancer treatments by dosing schedule were also recorded by line of therapy. For each treatment, the reason for its selection, its therapeutic intent (palliative vs life extension), and the duration of use is provided by the physician. For treatments which had already been discontinued, the duration of therapy, the reason for the treatment change, and best treatment response is recorded. Supportive care information (eg, antiemetics, erythropoietin stimulating agents, and bone protectants) was also collected.

\section{Platinum sensitivity}

Patients who were treated with a platinum-based 1L therapy and had 2L treatment information were categorized based on their PS. Patients who progressed or relapsed within 3 months after completion of $1 \mathrm{~L}$ platinum therapy were considered PR; patients who progressed or relapsed $\geq 3$ months after completion of $1 \mathrm{~L}$ platinum therapy were considered PS as per NCCN guidelines.

According to NCCN guidelines, the PS population was further split into patients relapsing $>3$ months but $\leq 6$ months (where treatment with a different systemic therapy is recommended) and $>6$ months where the NCCN guidelines recommend that the patient be re-challenged with the initial systemic therapy received in $1 \mathrm{~L}$.

\section{Statistical analyses}

Demographics, general health history, and disease and treatment history were reported descriptively using frequencies and percentages for categorical variables and means and standard deviations (and/or medians and ranges for skewed distributions) for continuous variables. Differences across a priori selected groups (ie, country/region, extensive vs non-extensive disease) were examined using chi-squared tests and one-way ANOVA tests for categorical and continuous variables, respectively. Kaplan-Meier curves were calculated for treatment persistence. Cox regressions were used to model persistence using available demographic, general health history, and disease history variables. Parameter estimates, standard errors, $P$-values, hazard ratios, and 95\% CIs around those hazard ratios were calculated.

Prevalence estimates for PS and PR were calculated for each country; 95\% CIs were also calculated for these estimates. Differences in the prevalence of PS and resistance were compared across countries using chi-squared tests. Differences between patients who were PS and PR were 
examined with respect to demographics, general health history, and disease history using chi-squared tests and one-way ANOVAs. Subsequent generalized linear models, specifying a binomial distribution and logit function, were conducted to predict platinum sensitivity/resistance from available demographic, general health history, and disease history variables.

Differences between treatment patterns in $2 \mathrm{~L}$ patients who were platinum-sensitive and platinum-resistant were examined using chi-squared tests. Additional analyses subdivided the platinum-sensitive group into those who relapse between 3 and $\leq 6$ months and those who relapse $>6$ months and compared $2 \mathrm{~L}$ treatment patterns by these three groups (the two PS groups and the PR group). These analyses were conducted separately by country. Differences across countries with respect to PS or PR treatment patterns were examined using chi-squared tests.

\section{Results}

A total of 6,936 patient charts were collected in this study. However, only 5,849 patients had extensive disease small-cell lung cancer (ED-SCLC) and were included in the analyses $(\mathrm{N}=2,203$ in the EU5, $\mathrm{N}=2,605$ in the US, and $\mathrm{N}=1,041$ in Japan). The mean age was 65.6 years $(\mathrm{SD}=8.8)$ and $66.3 \%$ were male (Table 1). The majority of patients were either current

Table I Demographics and health/disease history differences across line of therapy among patients with ED-SCLC (N=5,849)

\begin{tabular}{|c|c|c|c|c|c|}
\hline & \multicolumn{4}{|c|}{ Line of therapy } & \multirow[t]{2}{*}{$P$-value } \\
\hline & Total & IL & $2 \mathrm{~L}$ & $3 \mathbf{L}+$ & \\
\hline $\mathrm{N}$ & 5,849 & 4,294 & 1,160 & 395 & \\
\hline Country & & & & & $<0.001$ \\
\hline France & $256(4.4 \%)$ & 205 (4.8\%) & 40 (3.4\%) & II (2.8\%) & \\
\hline Germany & 736 (12.6\%) & 477 (1I.1\%) & $144(12.4 \%)$ & 115 (29.1\%) & \\
\hline Italy & 625 (10.7\%) & $513(11.9 \%)$ & $101(8.7 \%)$ & II (2.8\%) & \\
\hline Spain & $363(6.2 \%)$ & 295 (6.9\%) & 61 (5.3\%) & 7 (I.8\%) & \\
\hline UK & $223(3.8 \%)$ & I 88 (4.4\%) & 31 (2.7\%) & $4(1.0 \%)$ & \\
\hline US & 2,605 (44.5\%) & 1,965 (45.8\%) & $520(44.8 \%)$ & $120(30.4 \%)$ & \\
\hline Japan & I,04I (I7.8\%) & $65 I(15.2 \%)$ & $263(22.7 \%)$ & $127(32.2 \%)$ & \\
\hline Patient sex & & & & & 0.341 \\
\hline Female & 1,969 (33.7\%) & $\mathrm{I}, 43 \mathrm{I}(33.3 \%)$ & $392(33.8 \%)$ & $146(37.0 \%)$ & \\
\hline Male & $3,880(66.3 \%)$ & $2,863(66.7 \%)$ & 768 (66.2\%) & 249 (63.0\%) & \\
\hline Patient age, years & & & & & 0.060 \\
\hline Mean \pm SD & $65.6 \pm 8.8$ & $65.4 \pm 8.7$ & $66.0 \pm 9.2$ & $66.1 \pm 8.7$ & \\
\hline Patient age, years & & & & & $<0.001$ \\
\hline$<65$ & $2,536(43.4 \%)$ & I,9।8 (44.7\%) & $446(38.4 \%)$ & 172 (43.5\%) & \\
\hline 65 to $<70$ & $\mathrm{I}, 30 \mathrm{I}(22.2 \%)$ & 948 (22.1\%) & $279(24.1 \%)$ & 74 (I8.7\%) & \\
\hline 70 to $<75$ & I,086 (I8.6\%) & $76 \mid(17.7 \%)$ & $247(21.3 \%)$ & 78 (19.7\%) & \\
\hline 75 to $<80$ & $588(10.1 \%)$ & 440 (10.2\%) & 106 (9.1\%) & $42(10.6 \%)$ & \\
\hline 80 to $<85$ & 248 (4.2\%) & 167 (3.9\%) & $56(4.8 \%)$ & $25(6.3 \%)$ & \\
\hline $85+$ & 72 (I.2\%) & 51 (I.2\%) & $19(1.6 \%)$ & 2 (0.5\%) & \\
\hline Unknown & $18(0.3 \%)$ & $9(0.2 \%)$ & $7(0.6 \%)$ & $2(0.5 \%)$ & \\
\hline Ethnic group & & & & & $<0.001$ \\
\hline Black African & 372 (6.4\%) & $272(6.3 \%)$ & 81 (7.0\%) & 19 (4.8\%) & \\
\hline Caucasian & 4,105 (70.2\%) & $3,134(73.0 \%)$ & $736(63.4 \%)$ & 235 (59.5\%) & \\
\hline Far East Asian & $43(0.7 \%)$ & $33(0.8 \%)$ & $8(0.7 \%)$ & 2 (0.5\%) & \\
\hline Hispanic/Latin American & I 38 (2.4\%) & $97(2.3 \%)$ & $38(3.3 \%)$ & $3(0.8 \%)$ & \\
\hline Indian sub-continent & $14(0.2 \%)$ & $13(0.3 \%)$ & $\mathrm{I}(0.1 \%)$ & $0(0.0 \%)$ & \\
\hline Japanese & I,04I (I7.8\%) & $65 I(15.2 \%)$ & $263(22.7 \%)$ & $127(32.2 \%)$ & \\
\hline Middle Eastern & $16(0.3 \%)$ & $7(0.2 \%)$ & $6(0.5 \%)$ & $3(0.8 \%)$ & \\
\hline Mixed race & $7(0.1 \%)$ & $4(0.1 \%)$ & $\mathrm{I}(0.1 \%)$ & $2(0.5 \%)$ & \\
\hline North African & $19(0.3 \%)$ & $16(0.4 \%)$ & $3(0.3 \%)$ & $0(0.0 \%)$ & \\
\hline
\end{tabular}

(Continued) 
Table I (Continued)

\begin{tabular}{|c|c|c|c|c|c|}
\hline & \multicolumn{4}{|c|}{ Line of therapy } & \multirow[t]{2}{*}{$P$-value } \\
\hline & Total & IL & $2 L$ & $3 \mathbf{L}+$ & \\
\hline Other & $34(0.6 \%)$ & $30(0.7 \%)$ & $2(0.2 \%)$ & $2(0.5 \%)$ & \\
\hline Unknown & $272(4.7 \%)$ & $37(0.9 \%)$ & $21(1.8 \%)$ & $2(0.5 \%)$ & \\
\hline Smoking status & & & & & $<0.001$ \\
\hline Current smoker & 2,244 (38.4\%) & I,82I (42.4\%) & $327(28.2 \%)$ & $96(24.3 \%)$ & \\
\hline Former smoker & $3,249(55.5 \%)$ & $2,25 \mathrm{I}(52.4 \%)$ & $752(64.8 \%)$ & $246(62.3 \%)$ & \\
\hline Never smoker & 305 (5.2\%) & 189 (4.4\%) & $68(5.9 \%)$ & 48 (I2.2\%) & \\
\hline Unknown & 51 (0.9\%) & $33(0.8 \%)$ & $13(1.1 \%)$ & 5 (1.3\%) & \\
\hline BMI category & & & & & $<0.001$ \\
\hline Underweight & $168(2.9 \%)$ & $118(2.7 \%)$ & $31(2.7 \%)$ & $19(4.8 \%)$ & \\
\hline Normal & I,759 (30.1\%) & I,23। (28.7\%) & $364(31.4 \%)$ & 164 (4I.5\%) & \\
\hline Overweight & I,I08 (I8.9\%) & 834 (19.4\%) & $200(17.2 \%)$ & $74(18.7 \%)$ & \\
\hline Unknown & $2,64 \mathrm{I}(45.2 \%)$ & I,986 (46.3\%) & $531(45.8 \%)$ & 124 (31.4\%) & \\
\hline \multicolumn{6}{|l|}{ Comorbidities } \\
\hline Hypertension & $2,180(37.3 \%)$ & I,624 (37.8\%) & 432 (37.2\%) & 124 (31.4\%) & 0.041 \\
\hline Cardiovascular disease & $\mathrm{I}, 043(\mathrm{I} .8 \%)$ & $776(18.1 \%)$ & $203(17.5 \%)$ & $64(16.2 \%)$ & 0.615 \\
\hline Diabetes & 859 (14.7\%) & 631 (14.7\%) & 179 (I5.4\%) & 49 (12.4\%) & 0.341 \\
\hline Obesity & 338 (5.8\%) & 249 (5.8\%) & $65(5.6 \%)$ & $24(6.1 \%)$ & 0.936 \\
\hline Pulmonary disorder & 2,332 (39.9\%) & I,777 (4I.4\%) & $423(36.5 \%)$ & I 32 (33.4\%) & $<0.001$ \\
\hline Liver disorder & 200 (3.4\%) & 149 (3.5\%) & $32(2.8 \%)$ & 19 (4.8\%) & 0.144 \\
\hline Renal disorder & 296 (5.1\%) & $219(5.1 \%)$ & 58 (5.0\%) & 19 (4.8\%) & 0.963 \\
\hline Thyroid disorder & $268(4.6 \%)$ & $188(4.4 \%)$ & $50(4.3 \%)$ & $30(7.6 \%)$ & 0.012 \\
\hline Dementia/Alzheimer's disease & $42(0.7 \%)$ & $31(0.7 \%)$ & $9(0.8 \%)$ & $2(0.5 \%)$ & 0.859 \\
\hline Depression/anxiety & $249(4.3 \%)$ & 187 (4.4\%) & $48(4.1 \%)$ & 14 (3.5\%) & 0.728 \\
\hline Other comorbidity & $439(7.5 \%)$ & $343(8.0 \%)$ & $67(5.8 \%)$ & $29(7.3 \%)$ & 0.040 \\
\hline Number of concomitant conditions present & & & & & 0.004 \\
\hline Mean \pm SD & $1.39 \pm 1.12$ & $1.42 \pm 1.11$ & $1.33 \pm 1.08$ & $1.27 \pm 1.23$ & \\
\hline Months since diagnosis & & & & & $<0.001$ \\
\hline Mean \pm SD & $6.42 \pm 8.46$ & $3.76 \pm 5.77$ & $12.17 \pm 8.82$ & $18.48 \pm 12.35$ & \\
\hline ECOG & & & & & $<0.001$ \\
\hline 0 & $987(16.9 \%)$ & $778(18.1 \%)$ & $150(12.9 \%)$ & 59 (I4.9\%) & \\
\hline 1 & $3,503(59.9 \%)$ & $2,539(59.1 \%)$ & $756(65.2 \%)$ & $208(52.7 \%)$ & \\
\hline 2 & $1,152(19.7 \%)$ & 820 (19.1\%) & $217(18.7 \%)$ & 115 (29.1\%) & \\
\hline 3 & 73 (1.2\%) & 61 (1.4\%) & $6(0.5 \%)$ & $6(1.5 \%)$ & \\
\hline 4 & 16 (0.3\%) & $15(0.3 \%)$ & I (0.1\%) & $0(0.0 \%)$ & \\
\hline Stage at diagnosis & & & & & 0.002 \\
\hline Limited & 349 (6.0\%) & $240(5.6 \%)$ & $93(8.0 \%)$ & $16(4.1 \%)$ & \\
\hline Extensive & $5,500(94.0 \%)$ & 4,054 (94.4\%) & 1,067 (92.0\%) & 379 (95.9\%) & \\
\hline
\end{tabular}

Abbreviations: BMI, body mass index; ECOG, Eastern Cooperative Oncology Group; ED-SCLC, extensive disease small-cell lung cancer; IL, first-line; 2L, second-line; 3L, third-line.

smokers (38.4\%) or former smokers (55.2\%) and had a mean of $1.39(\mathrm{SD}=1.12)$ comorbid conditions. The most frequently cited comorbid conditions were pulmonary disorders (39.9\%), hypertension (37.3\%) and cardiovascular disease (17.8\%) (Table 1).

At the time of survey, patients were on average 6.42 ( $\mathrm{SD}=8.46$ ) months post-diagnosis, with $94.0 \%$ initially diagnosed as ED-SCLC (Table 1). The majority (73.4\%) of patients were treated in $1 \mathrm{~L}, 19.8 \%$ in $2 \mathrm{~L}$, and $6.8 \%$ in third-line (3L) or later (Table 1, Figure 1). Regional differences emerged in treatment reported, as per Table 2. Platinum + etoposide was the most common 1L therapy ( $83 \%$ of ED-SCLC patients), though it was significantly more common in the US $(87.0 \%)$ than the EU5 (82.1\%) or Japan (73.3\%) $(P<0.05)$ (Figure 2). By specific platinum, carboplatin + etoposide was 
3,000

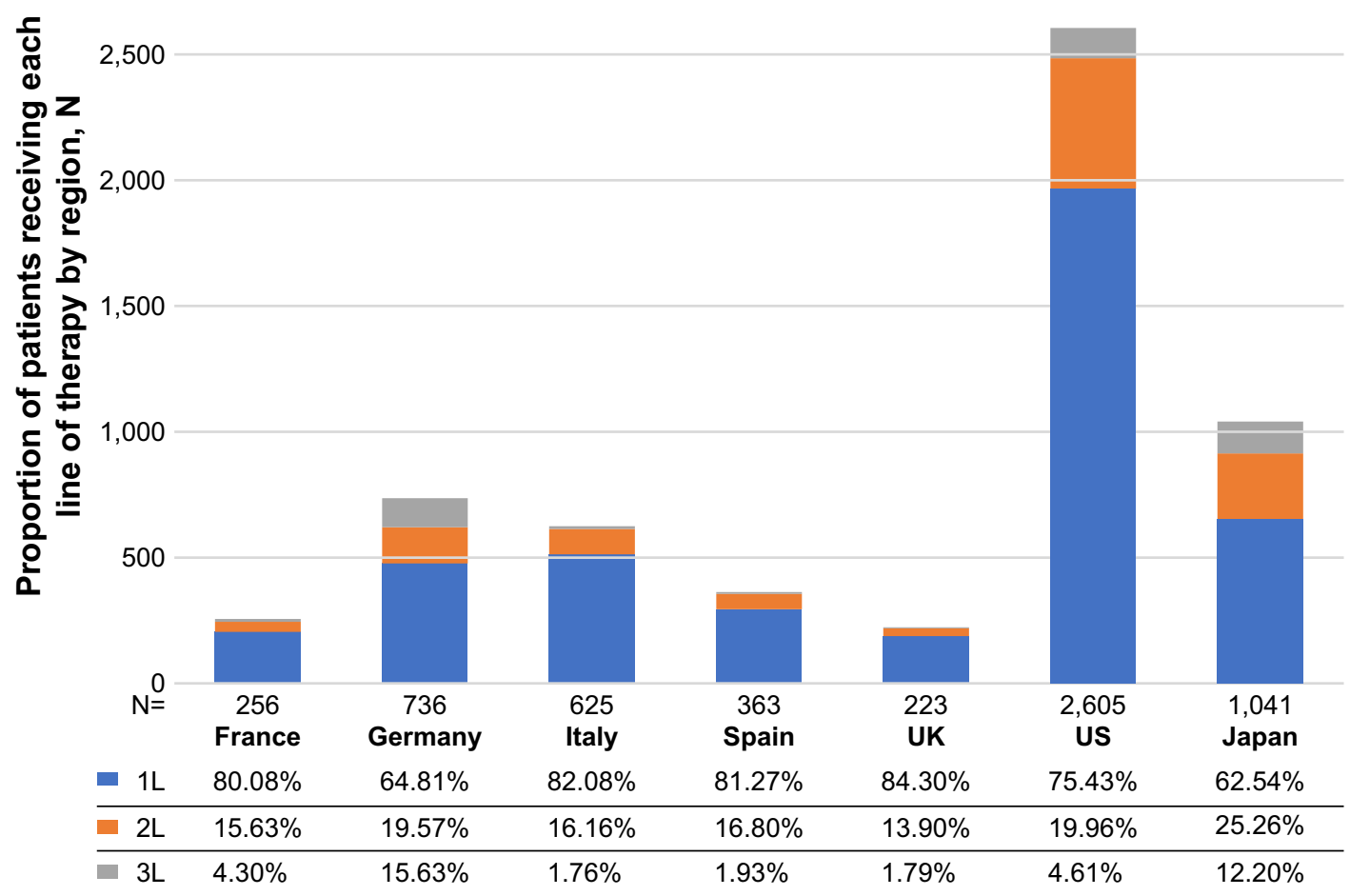

Figure I Regional treatment pattern differences for ED-SCLC.

Abbreviations: IL, first-line; 2 L, second-line; 3L, third-line; ED-SCLC, extensive disease small-cell lung cancer.

the most common regimen in all regions, but was administered more frequently in the US $(60.4 \%)$ than in the EU5 $(41.3 \%)$ or Japan (49.6\%). Cisplatin + etoposide was far more common in the EU5 (40.8\%) than in the US (26.6\%) or Japan $(23.7 \%)(P<0.05)$. Platinum + irinotecan was an uncommon $1 \mathrm{~L}$ treatment in the US $(2.0 \%)$ or the EU5 $(0.5 \%)$ but common in Japan $(22.7 \% ; P<0.05)$ (Table 2). PR (relapse within 3 months of $1 \mathrm{~L}$ completion) was observed in over $40 \%$ of patients (EU5: 40.9\%, US: 45.4\%; Japan: 56.1\%) following 1L therapy (Figure 3, Table 3).

Within each PR or PS sub-group the most common 2L treatment was topotecan (ranging from 34.6\% to $61.6 \%$ of patients; Figure 2) in the EU5 and US and amrubicin in Japan (ranging from $42.9 \%$ to $61.9 \%$ of patients). Among PR patients, 10.8\% (EU5), 27.3\% (US), and 36.4\% (Japan) of patients were administered a platinum-based therapy in

Table 2 Differences in IL treatment patterns across regions among patients with ED-SCLC $(\mathrm{N}=5,849)$

\begin{tabular}{|c|c|c|c|c|c|c|c|}
\hline & \multicolumn{4}{|l|}{ Region } & \multicolumn{3}{|l|}{$P$-value* } \\
\hline & Total & EU5 & Japan & US & EU5 vs US & EU5 vs Japan & US vs Japan \\
\hline$N$ & 5,849 & 2,203 & $|, 04|$ & 2,605 & & & \\
\hline Platinum + etoposide & $4,838(82.7 \%)$ & I,809 (82.1\%) & 763 (73.3\%) & $2,266(87.0 \%)$ & $<0.0001$ & $<0.0001$ & $<0.0001$ \\
\hline Carboplatin + etoposide & 3,000 (5I.3\%) & $910(41.3 \%)$ & $516(49.6 \%)$ & $1,574(60.4 \%)$ & $<0.0001$ & $<0.0001$ & $<0.0001$ \\
\hline Cisplatin + etoposide & I,838 (3I. .4\%) & $899(40.8 \%)$ & $247(23.7 \%)$ & $692(26.6 \%)$ & $<0.0001$ & $<0.0001$ & 0.0784 \\
\hline Platinum + irinotecan & $297(5.1 \%)$ & $10(0.5 \%)$ & $236(22.7 \%)$ & $51(2.0 \%)$ & $<0.0001$ & $<0.0001$ & $<0.0001$ \\
\hline Carboplatin + irinotecan & $88(1.5 \%)$ & $6(0.3 \%)$ & 45 (4.3\%) & $37(1.4 \%)$ & $<0.0001$ & $<0.0001$ & $<0.0001$ \\
\hline Cisplatin + irinotecan & $210(3.6 \%)$ & $5(0.2 \%)$ & 191 (18.3\%) & $14(0.5 \%)$ & 0.1073 & $<0.0001$ & $<0.0001$ \\
\hline Other platinum therapy & $342(5.8 \%)$ & $139(6.3 \%)$ & $9(0.9 \%)$ & $194(7.4 \%)$ & 0.1241 & $<0.0001$ & $<0.0001$ \\
\hline Other non-platinum therapy & $372(6.4 \%)$ & 245 (II.1\%) & $33(3.2 \%)$ & $94(3.6 \%)$ & $<0.0001$ & $<0.0001$ & 0.5499 \\
\hline
\end{tabular}

Note: ${ }^{*} P$-values calculated using Fisher's exact test.

Abbreviations: IL, first-line; ED-SCLC, extensive disease small-cell lung cancer; EU5, European Union 5 (France, Germany, Italy, Spain, and the UK). 

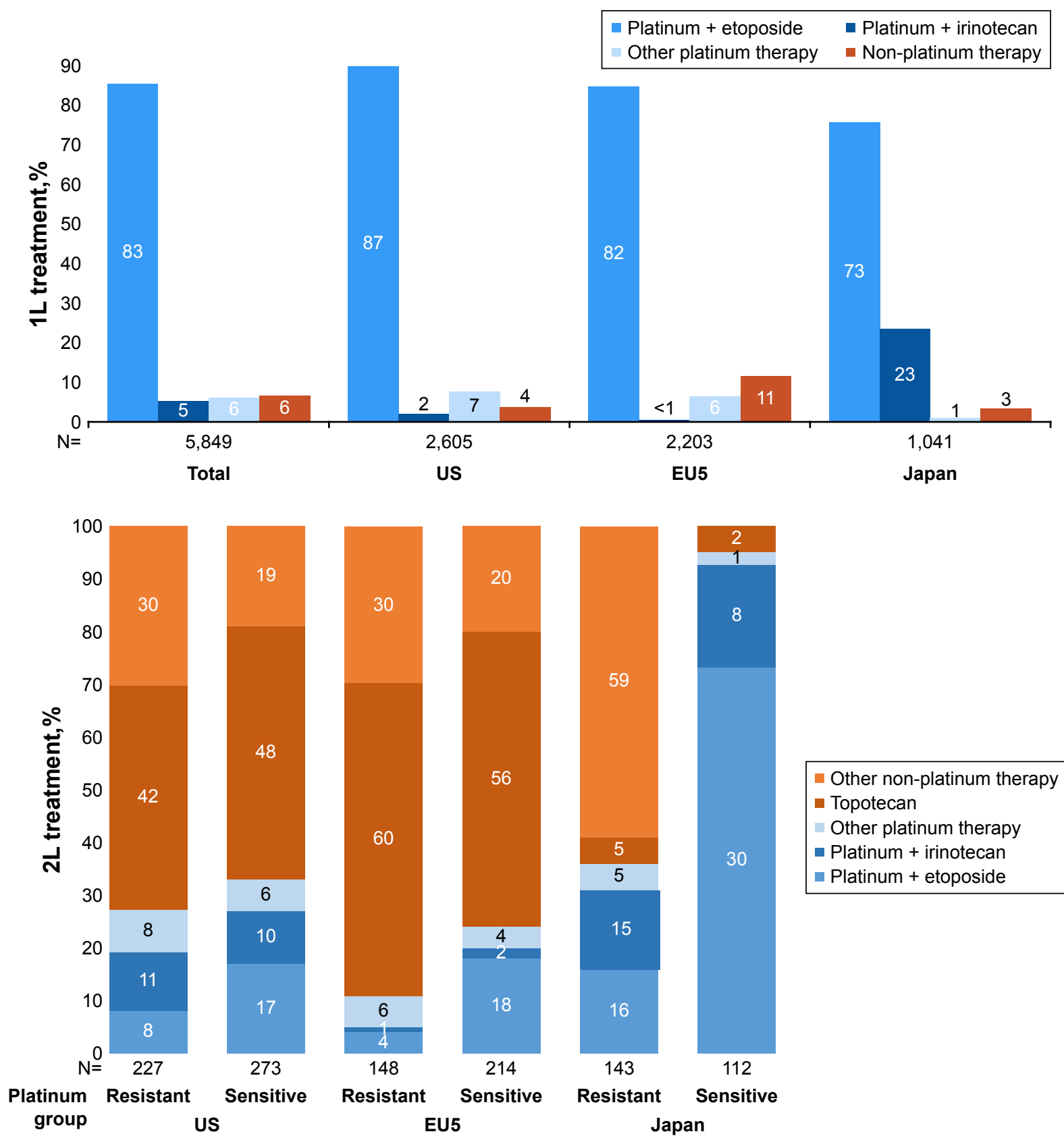

- Other non-platinum therapy
- Topotecan
Other platinum therapy
$\square$ Platinum + irinotecan
$\square$ Platinum + etoposide

Figure 2 Real-world treatment patterns for ED-SCLC.

Abbreviations: IL, first-line; 2L, second-line; ED-SCLC, extensive disease small-cell lung cancer; EU5, European Union 5 (France, Germany, Italy, Spain, and the UK).

2L (Table 4, sum of patients receiving PE and platinum + irinotecan and other platinum therapy).

\section{Discussion}

SCLC is an aggressive disease that is associated with a poor prognosis and limited treatment options. As noted, few realworld studies have evaluated treatment patterns based on PS and PR. The current study provides an insight into the treatment of SCLC in the US, Europe and Japan, and provides evidence of the unexpectedly limited role of PR in 2L therapy selection.
Additionally, this study contributes to creating and understanding the baseline treatment patterns prior to immuno-oncology therapies in a real-world setting. This baseline allows for future comparison of the incremental effects of IO therapies on the delivery of health care in the US, EU5, and Japan. In this study, several regional differences in $1 \mathrm{~L}$ treatment emerged. Patients treated in the US were most likely to receive PE therapy. Although carboplatin + etoposide was the most common regimen in all three regions, cisplatin + etoposide was more common in the EU5 compared with the US or Japan. 

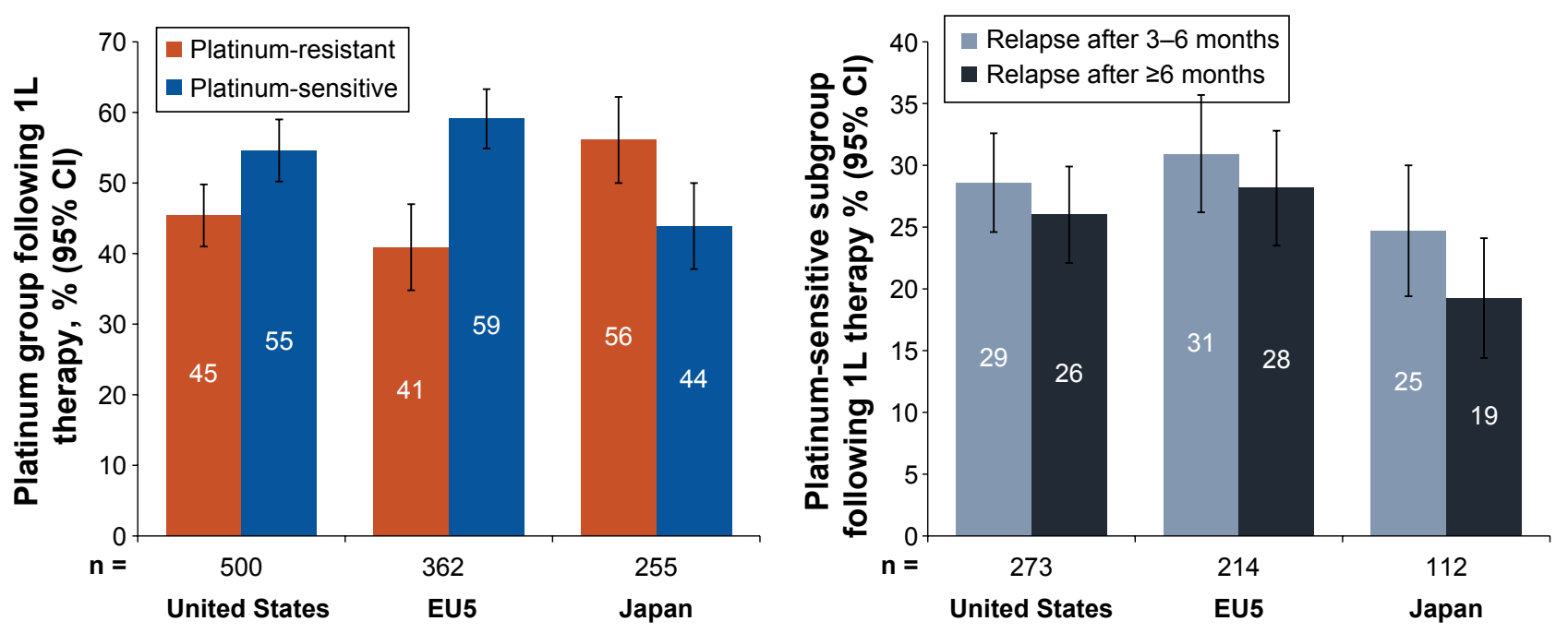

Figure 3 Real-world platinum resistance/sensitivity.

Abbreviations: IL, first-line; EU5, European Union 5 (France, Germany, Italy, Spain, and the UK).

Further, whereas platinum + irinotecan was uncommon among patients in the US and EU5, it was common in Japan, which may reflect evidence from trials among different patient populations driving treatment decision-making. Japanese patients treated with platinum + irinotecan had better outcomes with this combination when compared to the more common cisplatin + etoposide, however, these results were not replicated among European and US patient cohorts. ${ }^{22,23}$

Importantly, the results of the current study do not appear to align with current treatment guidelines published by ESMO and NCCN, and endorsed by JSMO regarding platinum sensitivity/resistance in $1 \mathrm{~L}$ as a factor guiding $2 \mathrm{~L}$ treatment. ${ }^{12,13}$ Published guidelines recommend that patients with PS disease should be re-challenged with their initial treatment whereas patients' who are PR should be treated with a nonplatinum alternative in $2 \mathrm{~L}$. In this study, a notable proportion of PS patients were switched to alternative therapies, while many PR individuals received platinum-based therapy as $2 \mathrm{~L}$ treatment, particularly in the US and Japan. These results further reinforce a previous US study by Parsons et al that found a relatively large number of SCLC patients received nonstandard treatments, irrespective of disease staging and prognosis. ${ }^{24}$

As noted previously, the benefit associated with platinum vs non-platinum-based therapies, as well as the most effective treatment for patients with refractory disease, remain open questions within the medical community. ${ }^{14,15}$ The paucity of clinical or empirical data pertaining to $2 \mathrm{~L}$ treatment among those diagnosed with SCLC is further highlighted in the ESMO guidelines, with treatment recommendations in this context based on studies with inadequate or nonexistent control groups and evidence suggesting limited or no clinical benefit to patients. Further, the NCCN guidelines pertaining to $2 \mathrm{~L}$ treatment are based on lower-level evidence. The current study findings reflect inadequate treatment options in $2 \mathrm{~L}$ for patients with $\mathrm{ED}$ SCLC and provide further insight into the unmet clinical need among this patient population.

There are several limitations to the present study that are important to consider. All patients were being administered an anticancer regimen; patients who are in between treatments, in active surveillance, or under purely palliative care were not represented. Further, patient selection was based on the most recent visit and patients who regularly visit their physician may have been more likely to be selected, and given the periodic data collection, it is possible that patients on shorter durations of therapy may not be fully represented. Finally, physicians in this study were recruited from internet panels and may not be representative of the broader population of oncologists, and by extension, their patients may not be representative of the SCLC patient population. As such, treatment patterns and other clinical data from this sample should be viewed cautiously when drawing inferences to the broader population.

Although nivolumab, a programmed cell death protein-1 checkpoint inhibitor, with or without the monoclonal antibody ipilimumab (nivolumab \pm ipilimumab) has just recently been included in the NCCN guidelines based on data from CheckMate 032 as an alternative to chemotherapy for $2 \mathrm{~L}$ treatment for patients with SCLC, its impact on our findings could be minimal as our study window ends in December $2016 .{ }^{12}$ For future research, it would be very interesting to 
Table 3 Prevalence of IL platinum sensitivity across country among patients with ED-SCLC who used platinum therapy in IL (N=I, I I 7)

\begin{tabular}{|c|c|c|c|c|c|}
\hline Country & Platinum group & $\mathbf{N}$ & $\%$ & $95 \% \mathrm{LCL}$ & 95\% UCL \\
\hline \multirow[t]{4}{*}{ EU5 } & Platinum-resistant & 148 & 40.9 & 34.8 & 47.0 \\
\hline & Platinum-sensitive & 214 & 59.1 & 54.9 & 63.3 \\
\hline & Platinum-sensitive ( $3-6$ months) & 112 & 30.9 & 26.2 & 35.7 \\
\hline & Platinum-sensitive (6+ months) & 102 & 28.2 & 23.5 & 32.8 \\
\hline \multirow[t]{4}{*}{ France } & Platinum-resistant & 20 & 57.1 & 40.7 & 73.6 \\
\hline & Platinum-sensitive & 15 & 42.9 & 26.4 & 59.3 \\
\hline & Platinum-sensitive ( $3-6$ months) & II & 31.4 & 16.0 & 46.8 \\
\hline & Platinum-sensitive (6+ months) & 4 & 11.4 & 0.9 & 22.0 \\
\hline \multirow[t]{4}{*}{ Germany } & Platinum-resistant & 61 & 43.3 & 35.1 & 51.5 \\
\hline & Platinum-sensitive & 80 & 56.7 & 48.5 & 64.9 \\
\hline & Platinum-sensitive ( $3-6$ months) & 50 & 35.5 & 27.6 & 43.4 \\
\hline & Platinum-sensitive (6+ months) & 30 & 21.3 & 14.5 & 28.0 \\
\hline \multirow[t]{4}{*}{ Italy } & Platinum-resistant & 25 & 26.0 & 17.2 & 34.8 \\
\hline & Platinum-sensitive & 71 & 74.0 & 65.2 & 82.8 \\
\hline & Platinum-sensitive ( $3-6$ months) & 34 & 35.4 & 25.8 & 45.0 \\
\hline & Platinum-sensitive (6+ months) & 37 & 38.5 & 28.8 & 48.3 \\
\hline \multirow[t]{4}{*}{ Spain } & Platinum-resistant & 27 & 45.8 & 33.0 & 58.5 \\
\hline & Platinum-sensitive & 32 & 54.2 & 41.5 & 67.0 \\
\hline & Platinum-sensitive ( $3-6$ months) & 9 & 15.3 & 6.1 & 24.4 \\
\hline & Platinum-sensitive (6+ months) & 23 & 39.0 & 26.5 & 51.4 \\
\hline \multirow[t]{4}{*}{ UK } & Platinum-resistant & 15 & 48.4 & 30.8 & 66.0 \\
\hline & Platinum-sensitive & 16 & 51.6 & 34.0 & 69.2 \\
\hline & Platinum-sensitive (3-6 months) & 8 & 25.8 & 10.4 & 41.2 \\
\hline & Platinum-sensitive (6+ months) & 8 & 25.8 & 10.4 & 41.2 \\
\hline \multirow[t]{4}{*}{ Japan } & Platinum-resistant & 143 & 56.1 & 50.0 & 62.2 \\
\hline & Platinum-sensitive & 112 & 43.9 & 37.8 & 50.0 \\
\hline & Platinum-sensitive ( $3-6$ months) & 63 & 24.7 & 19.4 & 30.0 \\
\hline & Platinum-sensitive (6+ months) & 49 & 19.2 & 14.4 & 24.1 \\
\hline \multirow[t]{4}{*}{ US } & Platinum-resistant & 227 & 45.4 & 41.0 & 49.8 \\
\hline & Platinum-sensitive & 273 & 54.6 & 50.2 & 59.0 \\
\hline & Platinum-sensitive ( $3-6$ months) & 143 & 28.6 & 24.6 & 32.6 \\
\hline & Platinum-sensitive (6+ months) & 130 & 26.0 & 22.1 & 29.9 \\
\hline
\end{tabular}

Abbreviations: IL, first-line; ED-SCLC, extensive disease small-cell lung cancer; EU5, European Union 5 (France, Germany, Italy, Spain, and the UK); LCL, lower confidence limit; UCL, upper confidence limit.

conduct a US specific analysis based on more recent IPSOS Oncology Monitor data to reevaluate these adherence issues against this updated guideline.

Despite these limitations, this study also has several strengths. Compared with other available data sources (eg, electronic health record datasets), the OM dataset is collected through primary research and offers a consistent methodology across all countries. This allows a clearer interpretation of study findings when examining results across multiple countries and regions. Further, because the data are abstracted from physician records, information such as reasons for switching are easily obtained from the data without invoking business rules or attempting to impose natural language processing to extract such information from notes, as would be the case in electronic health record data. Overall, this study provides an insight into real-world treatment of SCLC that is lacking in the scientific literature.

\section{Conclusion}

There is a paucity of research comparing ED-SCLC treatment patterns across regions, as well as the possible influence of platinum sensitivity or resistance on prescribed therapy, 


\begin{tabular}{|c|c|c|c|c|c|c|c|c|c|c|c|c|c|}
\hline & 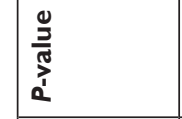 & & $\begin{array}{l}\overline{8} \\
\dot{0} \\
\dot{v}\end{array}$ & $\begin{array}{l}\bar{o} \\
\text { o. } \\
\text { v }\end{array}$ & $\begin{array}{l}\bar{\delta} \\
\dot{0} \\
\dot{v}\end{array}$ & $\frac{a}{0}$ & 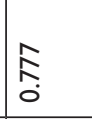 & స్ & $\frac{m}{n}$ & $\begin{array}{l}\tilde{n} \\
0 \\
0\end{array}$ & 蒿. & ָั & $\S$ \\
\hline & 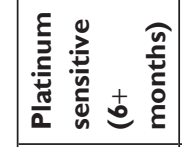 & $\underline{m}$ & 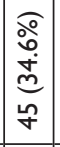 & 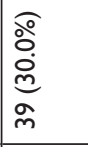 & 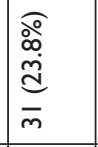 & 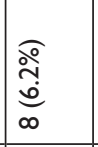 & 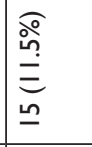 & $\begin{array}{l}\text { o̊ } \\
\stackrel{5}{5} \\
\text { o }\end{array}$ & 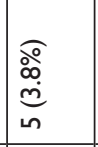 & 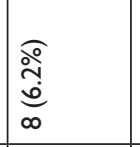 & 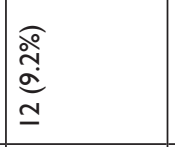 & 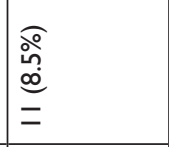 & $\begin{array}{l}\text { ○े } \\
\stackrel{0}{0} \\
\circ\end{array}$ \\
\hline & 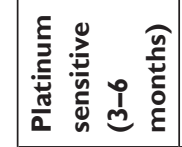 & $\underline{\underline{q}}$ & 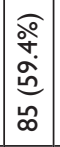 & 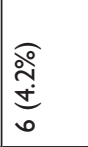 & 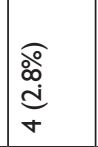 & 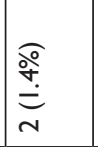 & $\begin{array}{l}\frac{\widehat{o}}{\bar{\sigma}} \\
\frac{\mathrm{c}}{\mathrm{m}}\end{array}$ & 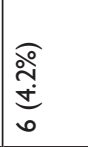 & 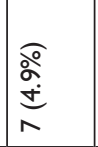 & 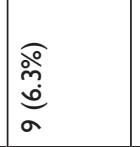 & 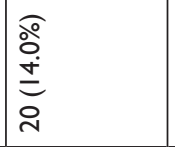 & 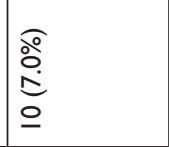 & 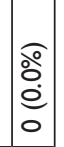 \\
\hline & 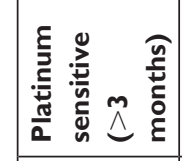 & $\underset{\sim}{\stackrel{n}{~}}$ & 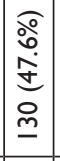 & 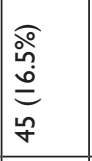 & 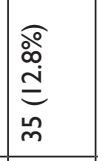 & 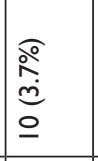 & 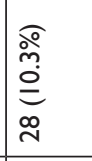 & 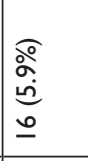 & 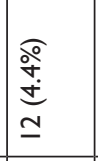 & 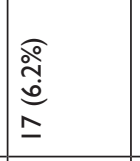 & 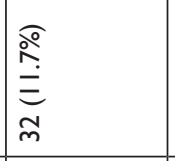 & 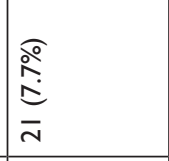 & 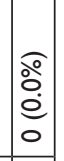 \\
\hline 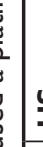 & 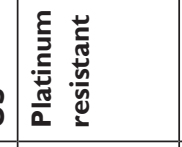 & $\hat{A}$ & 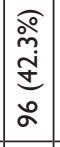 & 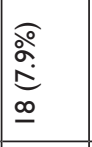 & 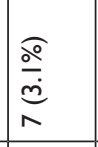 & 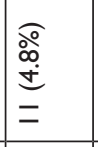 & 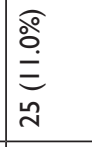 & $\begin{array}{l}\widehat{o} \\
\stackrel{+}{+} \\
\stackrel{+}{ \pm} \\
\end{array}$ & 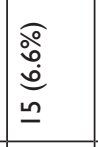 & 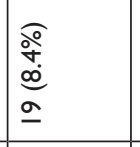 & 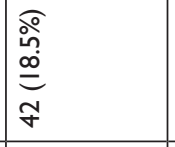 & 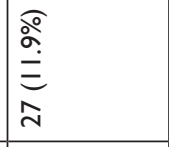 & 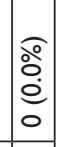 \\
\hline & 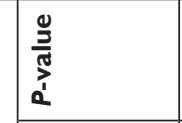 & & 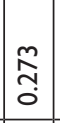 & ठั & 농 & $\begin{array}{l}\tilde{0} \\
0 \\
0 \\
0\end{array}$ & $\frac{1}{0}$ & $\begin{array}{l}0 \\
\text { Oे } \\
0\end{array}$ & $\frac{n}{0}$ & $\frac{1}{0}$ & \begin{tabular}{|l}
$\bar{\infty}$ \\
্ָ
\end{tabular} & $\frac{\text { Tे }}{0}$ & $\mid \begin{array}{l}\tilde{n} \\
\hat{n} \\
0\end{array}$ \\
\hline & 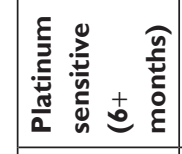 & $\frac{q}{q}$ & $\begin{array}{c}\text { } \\
\stackrel{0}{0} \\
0 \\
0 \\
0\end{array}$ & 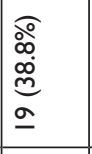 & 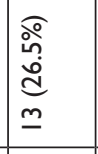 & 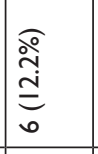 & 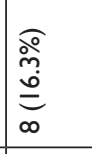 & 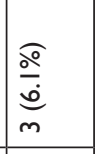 & 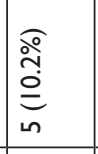 & 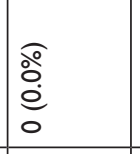 & $\begin{array}{l}\stackrel{ }{\circ} \\
\stackrel{d}{d} \\
-\end{array}$ & $\begin{array}{l}\bar{o} \\
\text { ò } \\
\dot{y} \\
\bar{y} \\
\end{array}$ & 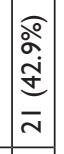 \\
\hline & 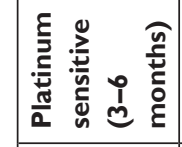 & ๓ & 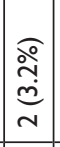 & $\begin{array}{l}\text { ঐे } \\
\text { ḋ̀ } \\
\text { t } \\
\end{array}$ & 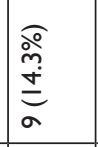 & 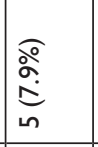 & 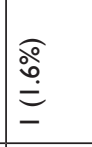 & $\begin{array}{l}\text { ○े } \\
\stackrel{0}{0} \\
0\end{array}$ & 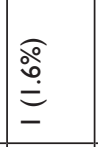 & 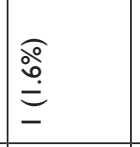 & 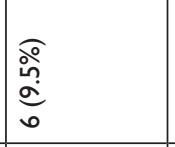 & 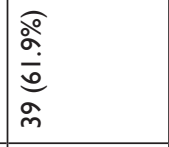 & 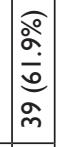 \\
\hline & 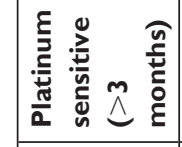 & $\cong$ & 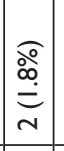 & 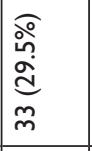 & 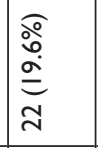 & 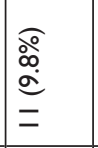 & $\begin{array}{l}\widehat{\circ} \\
\text { ò } \\
\infty \\
\alpha \\
\alpha\end{array}$ & 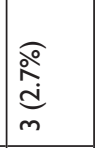 & 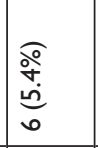 & 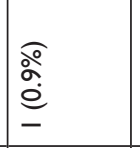 & 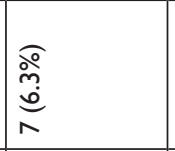 & 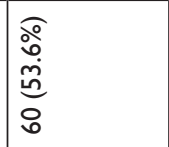 & $\begin{array}{l}0 \\
0 \\
0 \\
0 \\
0 \\
0 \\
0 \\
0\end{array}$ \\
\hline & 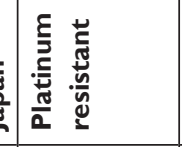 & $\underline{q}$ & 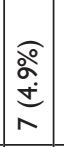 & 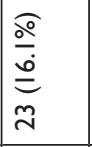 & 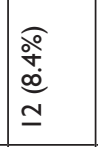 & 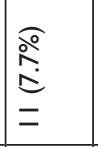 & 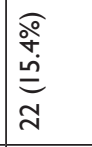 & $\begin{array}{l}\frac{\curvearrowright}{\sigma} \\
\stackrel{\rho}{\rho} \\
\underline{m}\end{array}$ & 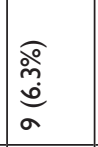 & 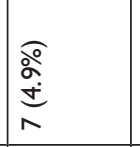 & \begin{tabular}{|l}
$\widehat{\circ}$ \\
$\stackrel{\circ}{\circ}$ \\
$\underline{0}$
\end{tabular} & 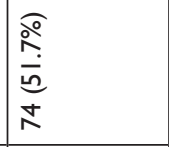 & 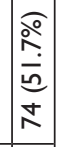 \\
\hline & 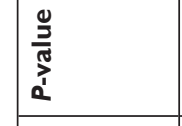 & & $\frac{\infty}{0}$ & $\begin{array}{l}\bar{a} \\
\dot{0} \\
\mathrm{v}\end{array}$ & $\begin{array}{l}\overline{8} \\
\text { Q } \\
\dot{0}\end{array}$ & mo & 文 & 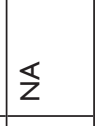 & 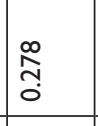 & ì & 过 & $\underset{0}{\stackrel{0}{1}}$ & $\mathbb{z}$ \\
\hline & 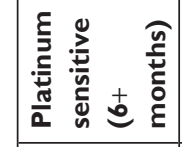 & $\underline{\text { }}$ & 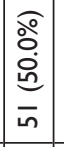 & 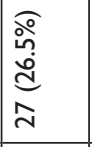 & 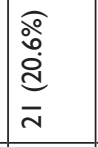 & 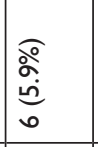 & 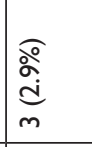 & $\begin{array}{l}\widehat{o} \\
\text { o. } \\
0 \\
0\end{array}$ & 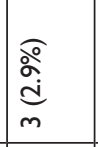 & 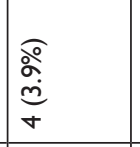 & 离 & 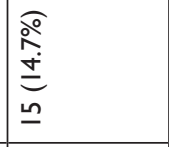 & ஓे \\
\hline & 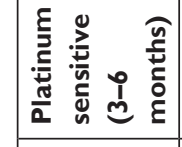 & $\cong$ & 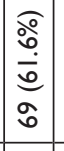 & 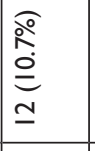 & 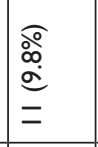 & $\begin{array}{l}\stackrel{\circ}{\circ} \\
\stackrel{0}{\varrho} \\
-\end{array}$ & $\begin{array}{l}\text { ळ. } \\
\stackrel{\circ}{\varrho} \\
\text { - }\end{array}$ & 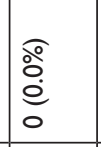 & 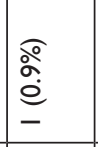 & 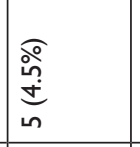 & 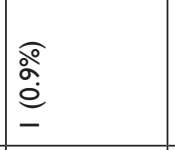 & 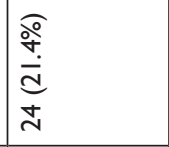 & 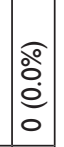 \\
\hline & 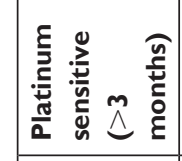 & $\frac{\pi}{4}$ & 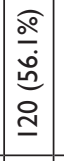 & 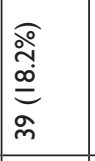 & 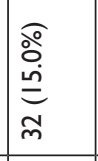 & 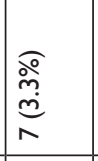 & 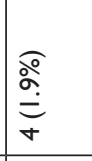 & $\begin{array}{l}\text { @̊ } \\
\stackrel{0}{0} \\
0\end{array}$ & 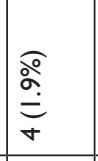 & 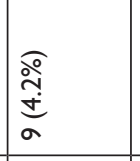 & $\underset{m}{\stackrel{o}{\stackrel{o}{\circ}}}$ & 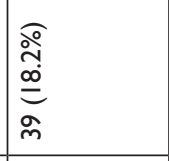 & $\begin{array}{l} \\
\stackrel{0}{\circ} \\
0 \\
0 \\
0\end{array}$ \\
\hline & 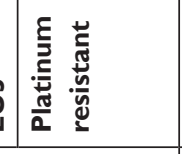 & 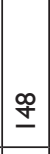 & 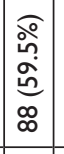 & 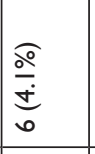 & 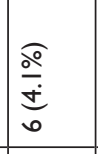 & $\begin{array}{l}0 \\
\text { o̊ } \\
0 \\
0 \\
0\end{array}$ & 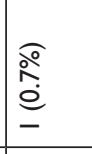 & 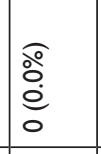 & 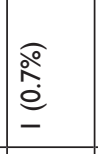 & 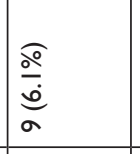 & \begin{tabular}{|l}
$\frac{\curvearrowright}{9}$ \\
$\stackrel{0}{6}$ \\
$\sigma$
\end{tabular} & 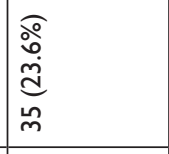 & 离 \\
\hline & & & 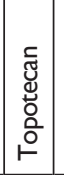 & 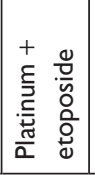 & 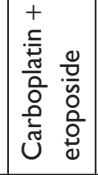 & 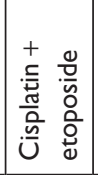 & 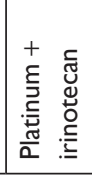 & 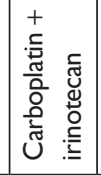 & 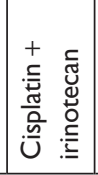 & 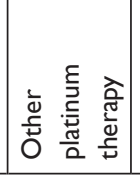 & 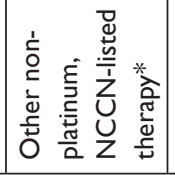 & 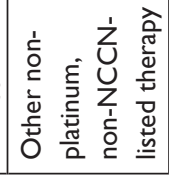 & 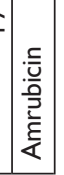 \\
\hline
\end{tabular}


despite the often poor prognosis, limited treatment advances, and challenges in 2L treatment. In this study, 94\% of patients with ED-SCLC across the US, Europe and Japan received $1 \mathrm{~L}$ platinum-based chemotherapy, but there were notable regional differences in the preferred regimen. Despite current guidelines from the NCCN and ESMO (endorsed by JSMO) recommending that platinum-resistant patients receive a different (non-platinum based) therapy in $2 \mathrm{~L}$, review of realworld treatment patterns showed that a substantial proportion of PR patients in the US and Japan were re-challenged with a 2L platinum-based therapy. Conversely, in PS patients where platinum re-challenge is recommended, a notable proportion were switched to non-platinum therapies in $2 \mathrm{~L}$. This study highlights the lack of a consistent paradigm for 2L ED-SCLC treatment, and reflects the limited therapeutic options and an unmet need in both PR and PS patients.

\section{Acknowledgments}

We acknowledge Errol J. Philip, PhD for providing writing assistance with this manuscript. This study was funded by Bristol-Myers Squibb.

\section{Disclosure}

Marco D DiBonaventura, Bijal Shah-Manek, and Karen Higginbottom were employed by Ipsos Healthcare (a consulting firm); John R Penrod and Yong Yuan worked for Bristol-Myers Squibb. The authors report no other conflicts of interest in this work.

\section{References}

1. Govindan R, Page N, Morgensztern D, et al. Changing epidemiology of small-cell lung cancer in the United States over the last 30 years: analysis of the surveillance, epidemiologic, and end results database. J Clin Oncol. 2006;24(28):4539-4544.

2. American Cancer Society. Cancer Facts and Figures 2017. Atlanta: American Cancer Society; 2017.

3. Riaz SP, Lüchtenborg M, Coupland VH, Spicer J, Peake MD, Møller H. Trends in incidence of small cell lung cancer and all lung cancer. Lung Cancer. 2012;75(3):280-284.

4. Kinoshita FL, Ito Y, Nakayama T. Trends in lung cancer incidence rates by histological type in 1975-2008: a population-based study in Osaka, Japan. J Epidemiol. 2016;26(11):579-586.

5. Ettinger DS, Aisner J. Changing face of small-cell lung cancer: real and artifact. J Clin Oncol. 2006;24(28):4526-4527.

6. Byers LA, Rudin CM. Small cell lung cancer: where do we go from here? Cancer. 2015;121(5):664-672.

7. Micke P, Faldum A, Metz T, et al. Staging small cell lung cancer: Veterans Administration Lung Study Group versus International Association for the Study of Lung Cancer - what limits limited disease? Lung Cancer. 2002;37(3):271-276.
8. Chute JP, Chen T, Feigal E, Simon R, Johnson BE. Twenty years of phase III trials for patients with extensive-stage small-cell lung cancer: perceptible progress. J Clin Oncol. 1999;17(6):1794-1801.

9. Schneider BJ, Kalemkerian GP. Personalized therapy of small cell lung cancer. Adv Exp Med Biol. 2016;890:149-174.

10. Beckles MA, Spiro SG, Colice GL, Rudd RM. Initial evaluation of the patient with lung cancer: symptoms, signs, laboratory tests, and paraneoplastic syndromes. Chest. 2003;123(1 Suppl):97s-104s.

11. Aarts MJ, Aerts JG, van den Borne BE, Biesma B, Lemmens VE, Kloover JS. Comorbidity in patients with small-cell lung cancer: trends and prognostic impact. Clin Lung Cancer. 2015;16(4):282-291.

12. Kalemkerian GP, Woo BW, Akerly W, et al. NCCN guidelines insights: small cell lung cancer, version 2.2018. J Natl Compr Canc Netw. 2018;16:1171-1182.

13. Fruh M, de Ruysscher D, Popat S, et al. Small-cell lung cancer (SCLC): ESMO clinical practice guidelines for diagnosis, treatment and follow-up. Ann Oncol. 2013;24(Suppl 6):vi99-vi105.

14. Amarasena IU, Chatterjee S, Walters JAE, Wood-Baker R, Fong KM; Cochrane Lung Cancer Group. Platinum versus non-platinum chemotherapy regimens for small cell lung cancer. Cochrane Database Syst Rev. 2015;99(3):CD006849.

15. Humeniuk MS, Kelley MJ. Second line treatment of small cell lung cancer: more is better? Ann Transl Med. 2016;4(Suppl 1):S65.

16. Postmus PE, Quoix E, Ardizzioni A. Small cell lung cancer in daily practice; SCOT registry (small cell lung cancer treatment and outcome). J Thor Oncol. 2013;11(Suppl 2):S339.

17. Gleeson M, Danese M, Lubeck D. Patterns of systemic treatment in US Medicare patients with extensive disease small cell lung cancer. IASLC Chicago Multidisciplinary Symposium in Thoracic Oncology. Chicago, IL: 2016.

18. Simos D, Sajjady G, Sergi M, et al. Third-line chemotherapy in smallcell lung cancer: an international analysis. Clin Lung Cancer. 2014; 15(2):110-118.

19. Gueron B, Kish JK, O’Day K, Martel MJ, Manley Daumont M. Patient count projections for advanced melanoma by line of therapy and other clinical characteristics in EU countries: results from the UK, Germany, France, Italy and Spain (EU-5). Value Health. 2014;17(7):A619.

20. Dibonaventura M, Higginbottom K, Meyers A, Morimoto Y, Ilacqua J. Treatment pattern differences across the United States, Western Europe, and Japan among patients with metastatic renal cell carcinoma. Value Health. 2016;19(7):A764.

21. Caldeira R, Scazafave M. Real-world treatment patterns for hormone receptor-positive, human epidermal growth factor receptor 2-negative advanced breast cancer in Europe and the United States. Oncol Ther. 2016;4(2):189-197.

22. Noda K, Nishiwaki Y, Kawahara M, et al. Irinotecan plus cisplatin compared with etoposide plus cisplatin for extensive small-cell lung cancer. N Engl J Med. 2002;346(2):85-91.

23. Lara PN, Natale R, Crowley J, et al. Phase III trial of irinotecan/cisplatin compared with etoposide/cisplatin in extensive-stage small-cell lung cancer: clinical and pharmacogenomic results from SWOG S0124. J Clin Oncol. 2009;27(15):2530-2535.

24. Parsons HM, Harlan LC, Stevens JL. Treatment of small cell lung cancer in academic and community settings: factors associated with receiving standard therapy and survival. Cancer J. 2014;20(2):97-104. 


\section{Publish your work in this journal}

Therapeutics and Clinical Risk Management is an international, peerreviewed journal of clinical therapeutics and risk management, focusing on concise rapid reporting of clinical studies in all therapeutic areas, outcomes, safety, and programs for the effective, safe, and sustained use of medicines. This journal is indexed on PubMed Central, CAS,

EMBase, Scopus and the Elsevier Bibliographic databases. The manuscript management system is completely online and includes a very quick and fair peer-review system, which is all easy to use. Visit http://www.dovepress.com/testimonials.php to read real quotes from published authors.

Submit your manuscript here: http://www.dovepress.com/therapeutics-and-clinical-risk-management-journal 